\title{
NORMALIZACIÓN FILOSÓFICA: ENTRE FILOSOFÍA Y CULTURA $^{1}$
}

\begin{abstract}
Aldo Ahumada Infante ${ }^{2}$
Resumen/Abstract

Este documento tiene dos propósitos. Primero, analiza lo que Francisco Romero (1891-1962) llamó la normalización de la filosofía - un concepto que explica el proceso de instalación de los estudios fílosóficos como una disciplina independiente en América Latina- y sus diferentes interpretaciones posteriores que, en términos generales, dividimos aquí en dos corrientes: la normalización como cierre y como reafirmación disciplinaria. Luego, usamos la categoría Romerian para identificar qué elementos de la cultura demostrarían que la filosofía se convirtió en una más entre las expresiones culturales en los países de América Latina (un rasgo distintivo de la normalización). Para ello, hemos seleccionado las ideas y conceptualizaciones que circulaban entre los filósofos chilenos de la época (primera mitad del siglo XX), que posiblemente también se hayan reflejado en otras expresiones artísticas y disciplinarias desarrolladas en el país.
\end{abstract}

Palabras clave: Francisco Romero, normalización filosófica, eurocentrismo, Latinoamérica, Chile.

PHILOSOPHICAL NORMALIZATION: BETWEEN PHILOSOPHY AND CULTURE

This paper has two purposes. First, it analyzes what Francisco Romero (1891-1962) called the normalization of philosophy - a concept that accounts for the process of installation of philosophical studies as an independent discipline in Latin America- and its different subsequent interpretations, which, in general terms, we divided here in two currents: normalization as closure and as disciplinary reaffirmation. Then, we use the Romerian category to identify what elements in culture would demonstrate that philosophy became one more among the cultural expressions in Latin American countries (a distinctive trait of normalization). To do this we have selected the ideas and conceptualizations that were circulating among Chilean philosophers at the time (first half of the 20thcentury), which were possibly also reflected in other artistic and disciplinary expressions developed in the country.

Keywords: Francisco Romero, philosophical normalization, Eurocentrism, Latin America, Chile.

\footnotetext{
${ }^{1}$ Este trabajo está basado en mi tesis: "Ideas de América Latina y de Chile en el período de "fundación" y "normalización" de la filosofía en Chile: el caso de Enrique Molina Garmendia" (2017), tesis para optar al grado de Magister. en Estudios Latinoamericanos, Universidad de Chile.

${ }^{2}$ Universidad Central de Chile. E-mail: ahumadainfante@gmail.com
} 


\section{Introducción}



Para dar inicio a nuestro trabajo, es preciso adelantar que para hablar de normalización filosófica se hace imperativo agregar la noción de fundadores de la filosofía a la reflexión, pues este es el concepto que utiliza Francisco Romero (1891-1962) para agrupar a los distintos pensadores latinoamericanos que países del continente y, por el otro, da inicio a los estudios filosóficos como disciplina profesional e independiente, lo cual -veremos- se identificará con la utilización de un particular "marco regulatorio" que nos dará la posibilidad de poder discernir qué podrá ser filosofía y qué operaciones reflexivas se alejan de esta etiqueta.

Además, advertiremos que hablar de normalidad y de fundadores (de la filosofía) es tomar una ínfima parte de lo elaborado por Francisco Romero. Y sería muy injusto comenzar este trabajo sin dejar esto establecido desde ya. De hecho, una de las importantes preocupaciones de nuestro autor fue el estudio sobre el hombre, el que puede ser revisado en diferentes trabajos de los cuales destaca Filosofía de la Persona (1944) y Teoría del hombre (1952). Además, Francisco Romero abordó temáticas referentes al conocimiento de la filosofía contemporánea de su tiempo, donde -además del interés por la filosofía europea- destaca la preocupación por el desarrollo de la filosofía en "las tres Américas, como lo muestran sus trabajos, artículos y epistolario" (Jalif de Bertranou, 2012: 139). En relación a ello, destacan obras sobre la historia de la filosofía moderna, filosofía de la cultura entre otros trabajos de variada índole filosófica. Estos estudios han quedado, lamentablemente, poco estudiados según refleja la mayoría de los trabajos elaborados por distintos pensadores latinoamericanos, frente al análisis de los conceptos de normalidad y fundadores. Esta situación no parece repetirse en otras latitudes, donde se revisa y estudia la obra de Romero desde una óptica más amplia; el caso de Estados Unidos es el más emblemático ${ }^{3}$. No obstante a lo recién mencionado, creemos importante el esfuerzo de realizar una relectura a los conceptos en cuestión. La tarea no es ociosa, responde a una interrogante que abarca una pregunta mayor referida a

\footnotetext{
${ }^{3}$ En referencia, es interesante el dossier sobre el epistolario de F. Romero de la revista Cuyo, Anuario de Filosofía argentina y americana, v.29, 2012., donde destacan para nuestro propósito los trabajos de Florencia Ferreira de Cassone, "Voces en diálogo: Francisco Romero y los Filósofos norteamericanos"; y el de Clara A. Jalif de Bertranou ya citado.
} 
la normalización de los estudios filosóficos en Chile, la cual, por motivos de espacio, sólo será posible insinuarla en las palabras finales ${ }^{4}$.

De todas formas, podemos ir adelantando que por normalidad filosófica se alude al proceso de profesionalización y mayor difusión de los estudios filosóficos en América Latina, lo cual habría ocurrido en la primera mitad del siglo XX, y habría traído consigo una suerte de 'clausura' en el pensamiento debido a la práctica y aprendizaje del filosofar europeo y norteamericano en menor medida. Más que el mero hecho de aprender una cierta "técnica" o "método" de filosofar, lo que se critica son las fijaciones y límites que se le ponen a la filosofía, dejándola así condicionada a la no aceptación de otras formas reflexivas que también podrían definirse como pensamiento filosófico. Varias de estas formas se vincularían a un cierto tipo de reflexión que estaría, según se plantea, anclado al sentir y pensar de buena parte de los grupos humanos que habitan esta parte del mundo. Parte de los intelectuales ligados las denominadas filosofías de la liberación de la década de los 70' serían parte protagónica de esta interpretación del proceso normalizador.

Si bien hay varios elementos rescatables de esta interpretación de la normalización, consideramos que hay otras lecturas de este proceso que, unidas a ciertos planteamientos de esta posición más bien crítica, logran ampliar el campo de percepción y el diagnóstico de esta supuesta "clausura" que forzaría, entre otras cosas, a priorizar lo foráneo a lo nuestro.

La lectura que proponemos, en cambio, tiene más que ver con el proceso de inserción de la disciplina filosófica en el campo cultural latinoamericano, que un trabajo exhaustivamente exegético sobre los conceptos de fundación y normalización de la filosofía ${ }^{5}$.Vista así las cosas, creemos que a tal diagnóstico de "clausura" que autores como Matías Silva (2009), José Santos-Herceg (2010; 2017), algunos "filósofos de la liberación" entre otros, habría que adherirle, creemos, más de un matiz.

Siguiendo una apreciación de Stefan Vrsalovic (2018) que, a su vez, es desprendida en parte de Horacio Cerutti, consideramos que a través de las distintas lecturas que han realizado autores posteriores a Romero,

\footnotetext{
${ }^{4}$ Para un análisis más extenso ver los capítulos 1 y 3 de mi tesis.

${ }^{5}$ Para estos fines, resulta útil el trabajo de Stefan Vrsalovic Muñoz (2018) "Entre dos interpretaciones de la normalización de la filosofía: ¿apertura o cierre de la filosofía latinoamericana?" (ver bibliografía), el cual analiza ambos conceptos con notable lucidez.
} 
tanto la normalidad filosófica como la categoría de fundadores de la filosofía en América Latina han logrado tomar prácticamente vida propia: alejándose algunas veces de las intenciones con las que el propio Romero las utilizaba, otras intentando cumplir con los alcances y límites que aquellos conceptos tendrían. Esto nos demuestra que estamos frente a conceptualizaciones nada de unívocas -especialmente cuando se habla de normalidad - , lo que podríamos interpretar como signo de ambigüedad; pero también podemos identificar el potencial de su uso. Aquellos conceptos han sido comentados, utilizados y reflexionados por diversos pensadores latinoamericanos, con distintas sensibilidades y posturas. A continuación, expondremos algunos antecedentes del autor, para luego ir avanzando en el análisis de las interpretaciones y usos que se les han dado a estas categorías.

\section{Antecedentes básicos del autor}

Francisco Romero nace en Sevilla en 1891; llega aún niño a Argentina en 1904, lugar donde hará toda su carrera intelectual hasta su muerte en 1962 en la ciudad de Buenos Aires. A la edad de dieciocho años comienza la carrera militar. Uno de sus profesores en aquel entonces fue J. Alfredo Ferreira, el cual ha sido denominado por Enrique Dussel como "el jefe del positivismo comtiano en Argentina" (1970: 81). Siguiendo con Dussel, nos dirá que este encuentro que establece Romero con el positivismo le "permitirá [...] conocer desde su juventud la posición filosófica que criticará en su edad adulta" (1970: 18). En 1931 nuestro autor abandona la vida militar para dedicarse en exclusiva a la investigación filosófica y al dictamen de cátedras. No obstante, Francisco Romero desde 1915 -según Dussel- comienza su caminar filosófico, inicio que tuvo carácter más bien asistemático y autodidacta. En la misma época comienza a estudiar el alemán, lengua que termina dominando como lector, no así a la hora de hablarlo (Dussel, 1970). En 1923 tiene uno de sus encuentros más importantes, y el que, en definitiva, marca su carrera como intelectual: el encuentro con Alejandro Korn. Korn, de hecho, es quien incentiva a Romero a abandonar la carrera militar. En Dussel lo vemos con estas palabras:

En 1930 convenció Korn a Romero de admitir a renunciar a la carrera militar para reemplazarlo como profesor de metafísica en la Facultad de Humanidades de La Plata. Desde 1928 estaba ya en la Facultad de Filosofía de Buenos Aires y un año después en La Plata. Pero sólo desde el 30 era profesor titular interino y comenzaba así su carrera de profesor universitario, abandonando su oficio de oficial de ingenieros en 1931. (Dussel, 1970: 82). 
De las cátedras impartidas por Francisco Romero en las universidades argentinas, una de las más destacadas será la que lleva el nombre de su maestro: la Cátedra Alejandro Korn. Aquella cátedra tenía un muy importante objetivo: hacer, de cierta forma, visible un pensar filosófico que, por ejemplo, en Chile y me arriesgo a asegurarlo- no aparece en los planes y programas de cátedra de ninguna de las universidades existentes en la época. En palabras de Juan Carlos Torchia:

Paralelamente a su labor personal (creativa, de enseñanza y de difusión) Romero realizó una tarea de promoción de la filosofía latinoamericana y de acercamiento y vinculación de jóvenes estudiosos. Utilizó para ello la Cátedra Alejandro Korn del Colegio de Estudios Superiores de Buenos Aires. Con este objeto, procuraba reunir y difundir información sobre instituciones y personas dedicadas a la filosofía en América Latina. (2009: 868).

Para los fines de este trabajo, repararemos en lo que Torchia denomina "la obra paralela" que realiza Romero, es decir, su interés por la historia, conocimiento y difusión del pensamiento filosófico latinoamericano. Nos interesa este punto porque los conceptos que hemos mencionado anteriormente, Romero los elabora precisamente para dicho propósito.

La realización y, podemos decir, misión de la cátedra Alejandro Korn, responde a un panorama que Romero no ve con ojos muy positivos. Según su diagnóstico, la filosofía en América Latina carece de diálogo consigo misma; los primeros intelectuales que elaboran reflexiones filosóficas de manera "profesional", disciplinar, los denominados "fundadores", lo hacen de manera aislada y en su mayoría de forma poco sistemática; idea, únicamente en este sentido, similar a la que Humberto Giannini realizara en $1978^{6}$, sólo que Romero lo hace unos cuarenta años antes aproximadamente.

Para revertir tal situación, Francisco Romero con ahínco realizó importantes conexiones con diversos intelectuales del panorama filosófico latinoamericano ${ }^{7}$, entre ellos contamos, por ejemplo, al chileno Enrique Molina Garmendia. Dicho sea de paso, creemos que la comunicación epistolar realizada por Romero y por varios otros de su tiempo como Molina y José Vasconcelos, tuvo a nuestro juicio el suficiente éxito para que palabras como: "Hay una condición previa para que se produzca una auténtica y continua reflexión en Latinoamérica y esta es que América empiece a hablar consigo misma y llegue a reconocerse" (Giannini, 1978: 32), queden algo extemporáneas para el año en que ellas son escritas. No

\footnotetext{
${ }^{6}$ Giannini, Humberto (1978). "Experiencia y Filosofía (a propósito de la filosofía en Latinoamérica), en Revista de Filosofía, 16 (1-2): 25-32.

${ }^{7}$ Ver Cuyo, Anuario de Filosofía Argentina y Americana, v. 29, 2012.
} 
por mero capricho un filósofo de la categoría de Francisco Miró Quesada denomina a Romero el "forjador" del diálogo filosófico en América Latina, el cual lo identifica como un "movimiento colectivo":

Lo colectivo es producto de un dinamismo objetivo-espiritual, de una dirección interna de la historia. Pero se realiza a través de personas individuales, de personalidades simbólicas. La energía del viento mueve el mar entero pero el oleaje se reparte en aisladas crestas de espuma. En el caso de la filosofía latinoamericana Francisco Romero destaca en primer término, es la cresta más elevada. (Miró Quesada, 1974: 121).

Como hemos visto, Francisco Romero es figura representativa del pensamiento filosófico en nuestra América, sería solamente una curiosa excepción el no incluir a este pensador argentino en una historia de la filosofía de esta parte del planeta. Más aún, si se trata de la filosofía que reafirma el contexto y el sujeto del filosofar latinoamericano. A continuación, desarrollaremos los conceptos romerianos en cuestión.

\section{Fundadores y Normalización de la Filosofía}

Para Romero, los denominados "fundadores" de la filosofía latinoamericana tienen nombre y apellido: Antonio Caso en México, Alejandro Deustua en Perú, el argentino Alejandro Korn, Enrique José Varona en Cuba, el uruguayo Carlos Vaz Ferreira y el chileno Enrique Molina. Los pensadores nombrados son los que inician un proceso que Francisco Romero denominará normalización, el cual percibirá mayores frutos en pensadores de generaciones posteriores. Estos pensadores nacen bajo el positivismo, corriente de pensamiento que, producto de la difusión y de la profundidad con que se recogieron ciertos "dogmas" de él, llegó a ser prácticamente un ethos en la América Latina de la segunda mitad del siglo XIX. Además, estos intelectuales son los que "transitan" de un pensamiento positivista a uno antipositivista que busca abrir el campo reflexivo a temáticas poco válidas en el Siglo XIX, el estudio de la intuición bergsoniana es ejemplo claro de esta búsqueda.

En síntesis, la historia podría resumirse del siguiente modo: positivismo, fundadores y luego normalización. Los fundadores serían los que "echan las bases para que se produzca la esperada y ansiada 'normalización' filosófica" (Cerutti, 1986: 87). Todo lo dicho anteriormente, Francisco Romero lo describe bajo los términos que siguen: 
Los fundadores de la filosofía latinoamericana, los hombres que filosofan por su cuenta y con resuelta consagración, pertenecen, salvo casos aislados, a la etapa positivista y al subsiguiente impulso antipositivista. Tras esta reacción contra el Positivismo, el interés filosófico se amplía, gana en hondura y continuidad y, podría decirse, se normaliza, acortando sucesivamente la distancia respecto a los países de vida filosófica intensa, en un afán por repensar los grandes temas de la actual problemática que se va consolidando, sin que hasta ahora haya logrado la autonomía. (Romero 1952: 11; énfasis añadido).

Los fundadores en términos simples son los pensadores que, lentamente, comienzan a abrir la filosofía al campo de la cultura. Son los hombres que paulatinamente comienzan a salir de un estado de aislamiento, de incomunicación entre sus pares a nivel continental. Uno de los rasgos de esta serie de maestros eminentes ha sido el aislamiento. Salvo una que otra excepción, estaban acostumbrados a la soledad, y hasta podría decirse que contaban con ella por adelantado: ni los desanimó ni se rebelaron contra ella (Romero, 1951: 148-149).

Romero identifica este problema y realiza una especie de diagnóstico histórico en el pensamiento latinoamericano, aquel diagnóstico fue el despertar que tuvo la filosofía en la América Latina a inicios del siglo XX, despertar que, como hemos visto, va en sincronía con la disminución de la concepción positivista en los filósofos nuestros.

Su capacidad y energía, la magnitud del esfuerzo que debieron cumplir no necesitan ser ponderados: maestros de sí mismos, nada han debido sino a su propio esfuerzo, y se aplicaron a una tarea que ni tuvo el estímulo del auxilio magistral ni se vio incitada por una consideración o respeto general hacia este género de estudios. A veces ejercieron influjo en pequeños núcleos; a la larga el resultado de su magisterio ha sido grande, mayor probablemente de lo que ellos mismos esperaban (Romero, 1951: 148).

Esto no quiere decir en absoluto que en este período hubo un distanciamiento radical al positivismo, sino más bien es un alejamiento que deja ciertos vestigios, más en algunos menos en otros; en Molina, por ejemplo, tenemos vestigios que no desaparecerán del todo ya que el positivismo estatuyó un rigor que tiene la suficiente importancia para ser reconocido como influencia a la hora de hacer filosofía. Sobre los fundadores, Romero nos dirá lo siguiente: 
En los combates contra el Positivismo se aumenta este grupo con pensadores ilustres, que vienen a completar el equipo de los que merecen ser llamados los fundadores, es decir, aquellos que, por la capacidad especulativa, la autenticidad de la vocación y la autoridad moral (esto último tan importante en cualquier tentativa de ensanchamiento espiritual), echan las bases del pensamiento filosófico iberoamericano, que hoy se desenvuelve en gran parte bajo su advocación y reconociendo su influencia directa o indirecta, por obra del estímulo, el ejemplo, el magisterio o el aporte doctrinal. (1952: 13; cursivas añadidas).

En otras palabras, Romero denomina "fundadores" a los primeros filósofos que, de una u otra forma, diseminan la conciencia filosófica en el campo cultural latinoamericano. Nada fácil, pues por circunstancias propias de su época el tiempo dedicado a la labor filosófica estuvo compartido con otros quehaceres. Sobre esto, Carlos Ossandón indica que el mérito de los fundadores, "consiste precisamente en haber sentado las bases, en un medio difícil y no preparado para ello, de un trabajo filosófico regular y con perspectiva de originalidad" (1984: 73). Tienen la gracia entonces de instalar esta disciplina en el campo cultural de sus respectivos países. En palabras del argentino, nuestros filósofos de inicios del XX:

Filosofaron e hicieron además muchas otras cosas, y por lo general con energía y clarividencia; contribuyeron de varios modos al progreso espiritual de sus patrias, y su aporte fue así más efectivo y oportuno que si se hubieran apartado en una reclusión que en su caso fuera egoísmo. El examen de sus escritos pone de manifiesto la seriedad de una información obtenida con ingente sacrificio y empeño, la hondura de una meditación que no tiene que envidiar en calidad a la de las más famosas inteligencias de otras culturas (Romero 1951: 154).

Una característica que no podemos dejar pasar sobre los fundadores nos la indica Guillermo Silva; para él, "la importancia mayor de este nuevo grupo radica más bien en haber hecho una amplia difusión de la filosofía, no en haber generado escuelas filosóficas que continuaran sus propios puntos de vista" (Silva Martínez, 2009: 268). Es decir, es el grupo que instala y, a su vez, dibuja ciertos prístinos límites para poder identificar de qué hablamos cuando hablamos de filosofía.

Como hemos visto, a inicios del siglo XX la filosofía se estaría haciendo cada vez más sistemática, rigurosa e independiente. Así, la labor se distancia del trabajo de otras expresiones como la historia y la pedagogía. En palabras de Raúl Fornet-Betancourt:

Para Romero, pues, los "fundadores" fundan tradición filosófica desde la soledad de su personal vocación filosófica; y es por ello que su acto 
fundador marca una radical inflexión en la vida intelectual de América Latina, a saber, la aparición de la filosofía como una función de la cultura. Lo que significa que, en la cultura iberoamericana, que "había preferido hasta ahora los estudios de índole literaria e histórica", suena la hora de la reflexión filosófica pasándose así a una nueva etapa de madurez intelectual (2000: 120).

Este nuevo renacer de la filosofía de carácter más especulativo, para validarse ante otras disciplinas, y con ello abrirse espacio, habría entrado en un cierto "proceso de purificación" consistente en el cada vez mayor empleo de métodos y regulaciones propias de las escuelas de pensamiento filosófico europeo (también de EE.UU. entre otros países excepcionales). A este proceso, Francisco Romero lo denomina normalización de la filosofía.

La normalidad filosófica es una categoría que tiene ciertas complicaciones a la hora de abordarla. Las interpretaciones que existen, como hemos mencionado, no son para nada unívocas. Sin embargo, creemos posible separar las aguas al menos en dos principales corrientes. Existen, a grandes rasgos, aquellos pensadores que encuentran en la normalidad filosófica un proceso de ahondamiento en la reflexión, la que incluye el aprendizaje de una "técnica" que debe internalizarse para así elaborar filosofía, no diremos verdadera, pero sí ceñida a ciertas normativas que indicarían estar frente a una filosofía universal abstracta producida en América Latina. Estos pensadores, de los cuales destacaremos a Risieri Frondizi, verían la filosofía como una reflexión de problemáticas transversales, es decir, "la filosofía sería una ciencia (sea de conceptos o de la realidad) y, como tal, los principios e inferencias a los que llega, intentan ser universalmente válidos" (Gracia; Jaksić, 1983: 16). Tal como la física o la biología, la filosofía es o debiese ser una: ¿se podrá hablar de la biología africana o europea? O bien ¿se podrá encontrar una física auténticamente latinoamericana? La respuesta más lógica sería que no hay tal diferenciación porque la biología es una disciplina global. Continuando con esta vertiente, podríamos indicar que la filosofía en esta parte del planeta, gracias a la normalización filosófica, tuvo la posibilidad de entrar en el "concierto universal de la filosofía", ya que ella nos brindaría el rigor necesario para ser parte y no estar ajenos, al menos no tanto, al desarrollo y progreso disciplinar.

Por otro lado, están los que sospechan de este proceso de normalización. Este grupo de pensadores, de variada índole y temporalidad, tendrán sus reparos y distancias a la hora de aproximarse a este concepto explicativo de nuestra historia de la filosofía. Tal normalización estaría más bien vinculada a un proceso de "encubrimiento" y copia, ¿copia a qué? ¿a quién?: la respuesta puede pasar por pueril obviedad, pero a 
la vez es innegable. Se copian los modos del pensar europeo y según el modelo que ellos dicten será el modelo válido, sin posibilidad de salirse de ese cauce por existir el temor de producir filosofía de segunda mano, o bien simple ensayística con diversos grados de inteligencia de elaboración. Desde esta normalización "crecerá así la comprensión para el esfuerzo serio, la estima para el aporte válido; disminuirá el aprecio hacia la improvisación brillante, hacia cualquier conato de suscitar la sorpresa o el deslumbramiento." (Romero, 1951:150). En fin, "la categoría de normalidad permite [permitiría] distinguir entre la filosofía y los híbridos que no merecen llevar ese nombre" (Santos-Herceg, 2010: 112). Así las cosas, la normalidad filosófica sería una "clausura" para el pensamiento filosófico en nuestra América. Aprender las formas del filosofar tal como se realizan en los países productores de conocimiento "serio", vendría a ser un nuevo ajuste de tuercas del pensar eurocentrado. En otras palabras, la normalización filosófica no sería una categoría "simplemente descriptica, pues lleva consigo una clara intención reguladora, normativa." (Santos-Herceg, 2017: 340). Como hemos podido apreciar, desde esta óptica la normalización poco habría contribuido a un pensamiento de carácter más propio, pues el bosque de voces europeas dificultaría el desarrollo de un pensamiento filosófico emanado de la propia experiencia circundante.

Ni una ni otra de las posturas es fácil de invalidar, al fin de cuentas ambas están dando cuentas del mismo proceso, sólo que unos no ven de manera tan negativo este proceso; y otros consideran que tiene consecuencias poco felices, pues con la normalización se habría instalado una concepción lo suficientemente estrecha de filosofía como para obstruirle el paso a otras experiencias reflexivas.

No obstante, consideramos que tanto la labor de los denominados fundadores, como el proceso de normalización, responden a un período de apertura a nuevas inspiraciones filosóficas; las que cargaron con sus respectivas cruces de las cuales, quizá de cuántas, nos hemos liberado para tomar prestadas otras tantas. Con todo y así, hemos considerado a este período histórico como un nuevo recomienzo de la filosofía. Lo que planteamos no tiene gran novedad, Leopoldo Zea y Arturo Andrés Roig, entre otros, lo han tomado de similar forma. Pero agregamos que con estas nuevas formas y métodos de pensar la filosofía que germinaban a inicios del siglo XX, también se abren nuevas formas de "interrogarnos", de vernos y asimilarnos. 
Este recomienzo trae consigo, además, ciertas ideas de América Latina que a veces pasan desapercibidas producto de la casi obsesiva misión de remarcarnos los nuevos límites que adquiere la disciplina filosófica en este período; y no se repara en cómo se van "filtrando" los imaginarios e ideas que se tienen de América Latina (y de los países que la conforman), y que están circulando en otras expresiones culturales del período; las cuales, además, y es lo que consideramos importante, también son tomadas como objeto de reflexión filosófica. Consideramos que esta forma de leer la normalización, como una disciplina que además de adquirir ciertas lógicas de cómo operar reflexivamente dentro de lo que se denomina filosofía, también adquiere ciertos "imaginarios operantes"8, al decir de Bernardo Subercaseaux (2011), que circulan en las distintas sociedades de América Latina.

Tomando específicamente el caso de Chile, que es el que nos consta, consideramos que debe intensificarse la investigación sobre las ideas de Chile y América Latina que circulaban en el período. Los filósofos chilenos de inicios del XX, al parecer, sí sociabilizaban sus opiniones sobre la realidad chilena y latinoamericana, al menos más de lo que se estima. Hemos detectado un cierto vacío en este campo de estudio ya que, pese a que suele decirse que estos pensadores poco se interesaban por los temas "propios", al ir a las fuentes, libros y revistas de la época, se tiene la impresión que ese parecer debe ser matizado debido a que las fuentes nos estarían mostrando otra historia.

\section{Normalidad como 'recomienzo'}

Habiendo anunciado las dos posiciones en las que suelen dividirse las lecturas sobre la normalidad filosófica, y siguiendo la concepción de Arturo Andrés Roig sobre el pensamiento latinoamericano, sostendremos que la normalización responde a un recomienzo del pensar filosófico en el continente. Vista las cosas desde esta perspectiva, creemos que la polaridad clausura/consolidación identificada en la mayoría de las lecturas realizadas a la conceptualización romeriana, puede ser matizada y así abrir otras lecturas.

Antes de aventurarnos, creemos que es necesario desarrollar esto de los "recomienzos". Como señalábamos anteriormente, la búsqueda de nuevas categorías que respondan a otras formas de pensar la realidad, diversas al positivismo, realizada por los filósofos de inicios del siglo XX, sumado a la mayor

\footnotetext{
${ }^{8}$ Cuando hablamos de 'pensamiento operante', nos referimos a un imaginario, una cierta noción (imagen) de algo que puede ser comprobado desde distintos ámbitos del espectro cultural de una sociedad, país, etc.
} 
comunicación y, por lo mismo, circulación de las ideas entre los pensadores latinoamericanos, nos hace pensar que estas nuevas búsquedas responden, también, a otras formas de leer e interpretar la propia realidad americana. Es decir, podemos identificar un recomienzo en las maneras de cómo pensarnos, un esfuerzo con todos sus errores y logros.

Para adentrarnos en los "recomienzos" del pensar latinoamericano que estipula Roig, primero debemos revisar lo que el mendocino denomina los modos de objetivación que realizaría un sujeto a la hora de pensarse, a la hora de autorreconocerse y de autoafirmarse como tal. No hay que olvidar que esos modos de objetivación "son, por cierto, históricos y no siempre se ha logrado, a través de ellos, una afirmación de subjetividad plena" (Roig, 2002: 109). Al ser históricos estos procesos son cambiantes; Roig nos dice que aquellos esfuerzos por reafirmarse como sujeto es un derrotero tedioso con pocos resultados exitosos, en sus palabras: "Más aun, diríamos que esa afirmación ha sido y es altamente defectiva, a tal extremo que nos vemos obligados a exponer nuestro pensamiento como sucesivos "comienzos" y "recomienzos", como una búsqueda de "huellas", o como una serie de 'emergencias"” (2002: 109).

Como vimos, el inicio del siglo XX nos brinda una nueva forma de reafirmación del sujeto que filosofa. El creciente distanciamiento a un modo del pensar, nos abre inevitablemente a otras preguntas. Recordemos que el pensamiento de corte positivista suele estar caracterizado por dejarle poco espacio a la especulación filosófica, enfatiza la búsqueda de certezas y es más bien reacio a la apertura de preguntas; por lo mismo, al aventurarse al estudio de sensibilidades filosóficas nuevas, nuevas serán también las formas de interrogarnos. Por dar un ejemplo elocuente: la libertad. Según nos dice Arturo Andrés Roig: Nuestros "fundadores" hablaron todos ellos sin excepción de "libertad" y su filosofía podría ser caracterizada para todo el continente como una "teoría de la libertad". Korn, Deústua, Caso, pusieron la libertad como categoría básica de su pensamiento (Roig, 1988: 365).

Si bien no desconocemos la opinión de que esta libertad expresada por los fundadores se basaría en un pensamiento cada vez más academicista y eurocentrado, el cual estaría más pendiente de su uso en el pensamiento europeo de avanzada que del uso que se le podría dar en las circunstancias y experiencia histórica propia de nuestra América, creemos ver un recomienzo del pensar.

En síntesis, a inicios del XX se logra identificar un sujeto latinoamericano que, por más que se suela reafirmar negativamente, realiza un 'nosotros' (sea cual sea) y busca ciertas salidas a la condición social, 
económica y del saber que se discierne del continente. Por último, este recomienzo en el pensamiento tiene vínculos con todo el proceso de reestructuración que viven los países latinoamericanos en términos políticos e históricos. Sobre los recomienzos, Roig nos dirá: “Cada etapa es un volver a empezar, por cierto, en un nivel que es el propio de esa etapa. Esta idea, eliminado el marco de la necesidad expresada en la relación "potencia-acto" que signa todo el proceso y en una prioridad del segundo, aun cuando no desarrollado, sobre la primera, es a nuestro juicio rescatable”. (Roig, 2008: 136).

En relación a esto, una cita que ayuda a explicar y aclarar los "comienzos y recomienzos" es la que nos brinda Vilma Figueroa Casas. Ella nos dice que:

Los conceptos de «comienzos» $y$ «recomienzos» de forma dialéctica responden en su teoría [la de Roig] a la búsqueda, a través de la historia de las ideas de los orígenes del pensamiento latinoamericano, de ahí que el comienzo sea de forma local, regional o continental, corresponden al pasado, al presente o al futuro, mientras que el recomienzo está relacionado con la renovación constante de las categorías, las influencias y los modelos metodológicos para enfrentar desde la historia de las ideas los comienzos de nuestra historia. (Figueroa Casas, 2000: 141).

Al renovarse tanto las metodologías como las categorías, estos comienzos y recomienzos corresponden a un sistema abierto. Así, se irán dando nuevos contenidos a conceptos ya utilizados. El tener en vista tales conceptos de Roig sirve para tener siempre presente que, tal como las formas de alienación y dominación se van rearticulando, las formas y mecanismos para enfrentarlas también deben ir variando. De esta forma, podemos afirmar que la historia de las ideas que propone Arturo Andrés Roig, con sus comienzos y recomienzos, busca a su modo el mismo objetivo que los teóricos de la modernidad/colonialidad: dar a conocer los diversos mecanismos que utiliza la colonialidad para prolongarse en el tiempo.

\section{Normalidad filosófica, entre la clausura y la consolidación disciplinar}

Retomando ciertas ideas, la normalidad filosófica nos daría ciertas claves para poder determinar, con juicio disciplinar, a qué escritura podríamos darle la venia de ser filosófica y cuál juzgar categóricamente de escritura ensayística, literatura, sociología, etc. En concatenación a lo anterior, con la normalidad, además, podríamos identificar a quién podríamos llamar filósofo. Este concepto serviría como guía, como modelo, nos daría ciertas facilidades de carácter más bien pedagógico para poder esquematizar la historia de la filosofía latinoamericana. En otras palabras, la "rayada de cancha" que elabora Romero al llenar de significado la normalidad como concepto analítico, articularía lo que hemos de entender hoy por hoy como filosofía académica y profesional, la cual sería un quehacer del pensamiento centrado en el análisis 
especulativo; en palabras de Romero: "Los hombres de esta etapa segunda hacen, en diferente medida, vida filosófica, es decir, ponen los intereses especulativos en la zona central de su espíritu" (1957: 13). Se debe agregar a esto la cada vez más amplia difusión de la filosofía a través de variadas instancias:

De este modo se van dando las condiciones externas favorables para una producción intensa y continuada, con la conciencia de participar en un trabajo solidario y conexo. La filosofía deja de ser vista como propensión arbitraria, caprichosa, y se aprovechan vocaciones, puesto que para profesarla con asiduidad no es ya indispensable el temple excepcional de los varones de la tanda anterior. En pocas palabras, se inicia una etapa de normalidad filosófica (Romero, 1951: 149-150).

En breve, la normalidad tendrá dos principales aristas: la expansión de la filosofía a través de la cultura mediante libros, conferencias y cursos, es decir "marca el ingreso de la preocupación filosófica en el común cauce cultural" (Romero, 1951: 149), y la profesionalización y colectivización de la filosofía, es decir, la salida del aislamiento de los pensadores para darle la paulatina bienvenida al diálogo entre pares, tanto a nivel de país como latinoamericano. Sobre este último punto Romero nos dirá lo siguiente: "Uno de los signos más promisorio es la voluntad de agrupación y de mutuo conocimiento entre quienes se consagran a la faena filosófica por profesión o vocación. Van surgiendo núcleos o sociedades en varios países, que reúnen a muchos, si no a todos los que en ellos trabajan en filosofía.” (1951: 151).

El diálogo que Francisco Romero realiza de forma sistemática con distintos pensadores del continente, lo consideramos como una de las más importantes contribuciones de este pensador para que "América comience a hablar consigo misma". Aquello se enmarcaría dentro de lo que Francisco Miró Quesada (1974) reconoce como el proyecto latinoamericano de filosofar. Desde este proyecto como base del pensar filosófico normalizado es que daremos pie a nuestra concepción de las categorías romerianas.

Partamos de una cita de Romero que será útil para seguir gravitando en torno a su percepción sobre la filosofía en América Latina de la primera mitad del siglo XX:

Veamos lo que entendemos por "normalidad filosófica" en este caso. Ante todo, el ejercicio de la filosofía como función ordinaria de la cultura, al lado de las otras ocupaciones de la inteligencia. No ya como la meditación o creación de unos pocos entendimientos conscientes de la indiferencia circundante; tampoco, por lo mismo, como la actividad exclusiva de unos cuantos hombres dotados de una vocación capaz de mantenerse firme a 
pesar de todo. Como cualquier oficio teórico, la filosofía permite y aun requiere el aporte de mentes no extraordinarias: basta el indispensable sentido para estos problemas, la seriedad, la información, la disciplina. (1951: 150).

Normalidad como algo aceptado y naturalizado, es decir, la filosofía no es algo extraño, ajeno a la cultura; la filosofía es con la cultura, es parte "Normal, porque la filosofía se convertía en una actividad 'normal', habitual, aceptada comúnmente, dentro de las actividades culturales" (Cerutti, 2009: 92). Entonces: "La normalización no solo tenía que ver, entonces, con la apropiación de la tradición filosófica universal (occidentalización), o con la instalación de un oficio entre otros (institucionalización) sino que, además, en el contexto latinoamericano, implicaba una toma de conciencia sobre el valor del filosofar en la conformación cultural de los pueblos." (Betancur, 2015: 146).

La reflexión filosófica de inicios del XX será entonces signo de avance cultural. Los pensadores anteriores a este nuevo "estado de la cultura", es decir los del siglo XIX, eran semillas dispersas que aún no estaban a tiempo de dar frutos en abundancia; Romero respecto a esto nos dirá lo siguiente: "En tiempos distantes se ha filosofado sin duda en la América de habla española y portuguesa, pero sin que ello atestiguase un interés notable por la intensidad ni por la extensión. O se filosofa en función de la cátedra, por exigencia de planes de estudio, o el interés personal era tan solitario que constituía rareza y quedaba sin eco efectivo." (1951: 148).

Como bien lo dice Horacio Cerutti, "de la docencia va pasando a la autonomía en la reflexión personal" (1986: 90). Con el crecimiento de la reflexión personal, viene la sistematización, la profesionalización y lentamente se "marca el ingreso de la preocupación filosófica en el común cauce cultural" (Romero, 1951: 149). Precisamente los llamados fundadores son los que comienzan a cimentar las bases de este proceso, ellos son los que brindan el clima filosófico idóneo: "los 'fundadores' viven esa contradicción, ese 'reparto entre la teoría y la vida', hasta que se va creando el ambiente académico y los filósofos pueden profesionalizarse." (Cerutti, 1986: 93).

Esta profesionalización es la parte que nos interesará ahora, ya que ella nos dará las bases para ver "qué es lo que constituye rigor, paciencia, fundamentación, calidad filológica, y qué es improvisación, guitarreo, charla de café, manipulación práctica de la filosofía (Cerutti, 2009: 97). De esta profesionalización es que se va a asumir una especie de punto cero, un inicio de la filosofía en América 
Latina. Por ejemplo, Leopoldo Zea nos dirá que con esta generación que se distancia del positivismo se dará inicio a una nueva época en la historia de la filosofía en América Latina, es decir, la época de la historia contemporánea de nuestro pensamiento (Zea, 1976). Para algunos autores, este inicio vendría de la mano con una cierta clausura del pensamiento, como ya lo hemos anunciado, cuestión que ahora lo analizaremos.

La normalidad como clausura del pensamiento, se debe leer como un pensamiento enajenado, alienado, que imita y no rebasaría las formas del cómo se filosofa en Europa. En palabras de José Santos-Herceg, "la idea de una "normalidad" es esencialmente cerrada y, por lo tanto, excluyente de todo otro tipo de filosofía que no sea la del tipo europeo-occidental.” (2017: 341). Desde esta óptica, la normalidad estaría ligada a un saber esclavo, un saber que ahondó en la ceguera, que no brinda caminos de salida a nuestra situación de sometimiento epistemológico. Para ello queremos dar la visión de dos pensadores que han sido parte de la(s) filosofía(s) de la liberación: Osvaldo Ardiles y Mario Casalla. Nos basamos en ellos por dos motivos esenciales. Por una parte, no han sido representantes muy visitados a la hora de revisar la producción elaborada por los pensadores que en la década de los setenta, bajo el nombre de filosofía(s) de la liberación, elaboraron un pensar crítico frente a las corrientes filosóficas europeas de moda; por otra, ambos han reflexionado de manera similar la conceptualización de normalidad filosófica, es decir, la consideran como un pensamiento y/o momento histórico que impulsa el pensar en los universales abstractos como tal, sin reparar en su evidente visión eurocentrada que impediría un pensar con rasgos de autenticidad .

Desde esta visión, Romero nos estaría impulsando a seguir -desde la arista de la filosofía- hacia una profundización de la "deformación planificada que han incorporado como 'cultura"' (Casalla, 1973: 38) las elites intelectuales latinoamericanas. La normalización sería una nueva clausura, y quizá la definitiva, hacia un pensar innovador. Causa de esto vendría a ser la importancia que se le da al comprender e imitar el cómo se hace filosofía en los países que en la década de los setenta los denominaban metropolitanos. Con respecto a esto Mario Casalla nos dirá lo siguiente:

Es así que, esta "reducción academicista" supone una compresión desarrollista de la labor filosófica. Europa habría fijado el modelo y los cánones del filosofar-de todo auténtico filosofar posible-al cual nosotros, los "primitivos" latinoamericanos, nos iríamos acercando más o menos gradualmente. El ideal de alcanzar la "normalidad filosófica" predicado por Francisco Romero sería el inicio en esta dirección. Pero, como el 
ingreso en dicha vía sería el ingreso "en la Filosofía sin más", se desprende, en consecuencia, la negación de cualquier particularidad geográfica o espiritual posible y el problema de un "filosofar latinoamericano" (en sentido estricto) queda desvirtuado y reducido al terreno de la anécdota o del folklore (Casalla 1973: 40).

En términos similares, Osvaldo Ardiles nos planteará que la normalización filosófica será ese quehacer reflexivo que por fin comienza a adquirir la técnica necesaria para crear pensamiento filosófico sin más. Vistas las cosas de este modo, en América Latina los pensadores deben seguir la onda de un pensar siempre novedoso, que dicho sea de paso siempre está afuera de nuestras fronteras. Hay que primero aprender y luego comenzar a filosofar. En palabras de Romero: "La naciente filosofía tiene que ir mucho a la escuela todavía; y aun se le debe incitar a que prolongue la escolaridad, porque todas las precocidades -y más la de la inteligencia- son peligrosas, y en los casos menos graves se resuelven en lamentables pérdidas de tiempo (Romero 1951: 153).

La filosofía en la América de habla hispana debe ir a la escuela, debe aprender cómo se piensa. En el fondo, Romero nos estaría diciendo que en Europa se piensa de un modo que se puede denominar - sin problemas- filosofía, mientras que acá aún se debe depurar el pensamiento, permitir un proceso de decantación, ya que el pensamiento filosófico latinoamericano es de baja ley; respecto a este proceso Osvaldo Ardiles, en una escritura que a mi juicio es de muy grata lectura, nos va a decir las siguientes palabras:

Manejábamos sus idiomas, emulábamos sus cátedras, utilizábamos su bibliografía, investigábamos sus fuentes con adecuado aparato erudito, nos apoyábamos en las diversas variantes de su "visión de mundo" (axiología, fenomenología existencial y ontológica, materialismo dialéctico, historicismo diltheyano u orteguiano, etc.), importábamos sus problemas y copiábamos sus soluciones. Con un poquito de suerte, podríamos lograr que nuestro disfraz fuese perfecto y pasar por distinguidos ciudadanos del mundo (del mundo metropolitano, claro está). Si hasta el acento vernáculo habíamos perdido. ¿Cómo podía ser de otro modo, si nos habíamos educado en francés, inglés o alemán; si los catálogos de las librerías y editoriales de París, Frankfurt o Londres casi no poseían secretos para nuestros curiosos espíritus? ¿Acaso no es eso cultura; no consiste en eso hacer filosofía? ¿Qué más podían exigirnos para darnos carta de ciudadanía en la prestigiosa "República metropolitana de Filosofía y Humanidades"? (1973: 20).

Lo que Ardiles nos comenta en la cita que acabamos de ver, es precisamente ese "ir a la escuela" del que nos habla Romero. Ahora, claramente vemos que tanto Casalla como Ardiles no verían con buenos ojos 
el proceso normalizador. Quizá el que se haya expandido el saber filosófico a través de nuestras culturas no sea el reparo, y hasta afirmaría que aquel proceso sí estaría valorado por estos pensadores, pero la forma del cómo se busca hacer filosofía es lo que se pone en cuestionamiento. Puesto que el ir a la escuela, como nos lo dice Romero, equivale a importar las ideas para reflexionar sobre ellas, y desde ellas -si es que hay cabida para ello-, poder reflexionar la realidad latinoamericana que distaría bastante de la situación social y cultural de donde nacerían estas filosofías. Este ir a la escuela era parte de esa "deformación planificada" de la que nos hablaba Casalla (1973). En Ardiles esto mismo se verá reflejado en las palabras que leemos a continuación:

Hacer filosofía, en esta "tierra extraña" y semibárbara, consistía en repetir continua y esforzadamente los tópicos de la dominación. Cuando la moda europea (diríamos, parafraseando a Sartre) gritaba: i"Positivismo"!, aquí se repetía jubilosamente: "...ismo". Cuando la voz de orden metropolitana imponía: "¡Tomismo!", aquí se contestaba sumisamente: "...ismo". Cuando las ondas hertzianas y el celuloide transmitían: "iExistencialismo!", nuestros receptores captaban sordamente: "...ismo." (Casalla 1973: 24).

Repetir y pensar desde lo repetido; caminar en caminos ya cimentados y delimitados por otros; creer y convencernos de que una filosofía auténtica era la que se producía en un lugar del cual no éramos parte; había que imitar ese pensar, esa técnica y por eso mismo es que los denominados fundadores de la filosofía en América tenían tal importancia, pues, desde ese momento es que la filosofía en América al fin ya adquiría algo más de seriedad. Filosofía sin más, universal y abstracta; respecto a esto Cerutti nos diría: "La noción de normalización filosófica perdió de vista que la filosofía es más academia que profesión y oscureció las connotaciones políticas del trabajo académico, como si profesionalizar significara privatizar." (Cerutti 2000: 116).

Estimo que Horacio Cerutti en esto tiene mucha razón, puesto que academia no es lo mismo necesariamente- que profesionalización, y más aún que esa suerte de profesionalización no debiese por qué dejar de lado los aspectos políticos que "contaminarían" la labor filosófica. Sin embargo, no hay que perder de vista que la reflexión filosófica realizada por los distintos pensadores de nuestra América del período, sí compartían ciertas ideas e imaginarios sobre la región que estaban circulaban en la cultura, los cuáles efectivamente eran tomados como objeto de reflexión. Quizá no mayoritario, pero no estaban ausentes. 
Retomando, tanto Ardiles como Casalla buscarán un pensamiento en situación, contextualizado, es decir, nacido de las entrañas mismas de la cultura de nuestros pueblos: única gestora de un filosofar de matiz propio. Desde esta perspectiva, la filosofía sí debiese ir a la escuela, es verdad, pero no a tomar las mismas asignaturas que Romero nos dice que este pensar debiese tomar. Aquí la mira estaría apuntando hacia otro lugar, es más, el lugar hacia a donde apuntaría una reflexión filosófica propia de nuestra América, obligaría a quien quisiera ver en -y pensar desde- ella, tener que darle la espalda a la tradición occidental/europea, al menos por el tiempo necesario para poder -y esta reflexión la recojo de Walter Mignolo (2003) - no solo cambiar el contenido de la conversación, sino también los términos de la conversación. Para esto, tanto Ardiles como Casalla buscarán una filosofía que denominan "pensamiento universal concreto o situado". Cito a Mario Casalla:

De este ejercicio de lo universal-situado hablamos propiamente, cuando utilizamos la expresión filosofía latinoamericana. En consecuencia, ella no es ni la variante geográfica de un pensamiento universal sin más, ni el agregado del "color local" a aquel supuesto modelo, ni la aplicación del modelo de filosofar eurocéntrico a temas específicamente argentinos o americanos. Muy por el contrario, trátese de la gestación de un horizonte ontológico (que nace de nuestra propia situacionalidad histórica $y$ cultural), desde el cual podemos reconocernos profundamente como pueblo (como comunidad de cultura) y, al mismo tiempo, participar creativamente (y no bajo la forma pasiva de la dependencia) del inexcusable diálogo planetario de las culturas. (Casalla 1986: 26-27).

Desde otro ángulo del pensador en situación, Osvaldo Ardiles nos dice:

Por lo tanto, todo lo que haga, lo realizará en y desde una situación histórica concreta que le imprimirá sus peculiares características. Y esto vale sobre todo para la filosofía. Originada en una situación concreta, cuando es genuina, asume desde dentro todos sus problemas e inquietudes, da cuenta de ellos comprometiéndose a fondo en la respuesta. Desde esta perspectiva, es lícito hablar de la posibilidad de una filosofía "americana" con proyección universal. En realidad, nunca ha existido una filosofía "universal". Lo que se ha dado históricamente ha sido una filosofía griega, romana, europea, etc., con atisbos de universalidad. (Ardiles 1973: 11).

Aquellos pensadores latinoamericanos que captaron en el proceso normalizador una lógica opresora, la cual, según su visión, iniciaba un proceso de clausura en el pensamiento, fueron parte de los que "le dieron vida propia" a la normalización, más allá, creemos, de las mismas proposiciones de Francisco Romero dentro del contexto en que estas reflexiones fueron hechas. De todas formas, creo que no es criticable intentar sacarle partido al uso de un concepto, sea para criticarlo o para reafirmarlo. Después de todo, la propuesta de lectura que sugerimos también es parte de eso. 
Otra lectura sobre el proceso de normalización, o bien del período en cuestión, será la que busca identificar una profundización en el saber filosófico. Desde aquí, el filosofar que se asoma a inicios del XX en América Latina, adquirirá un carácter más propio de su quehacer disciplinar, y con ello, una conciencia más clara a la hora de entender a qué se le debe denominar filosofía. Aquí el pensamiento no se vuelve a lo que se le podría denominar "pueblo" en los pensadores adscritos a las filosofías de la liberación de la década del 70, más bien la filosofía, podríamos decir, tendría un corte más academicista y a la vez más apegado a la "norma". Esto no quiere decir necesariamente que lo que se quiera hacer es un pensar eurocentrado, tampoco que la filosofía no se pueda crear en situaciones como la latinoamericana, ni siquiera que sólo se preocupa de un quehacer celosamente inmanentista. Sólo se espera que la labor filosófica sea una forma reflexiva particular que logre diferenciarse del quehacer de otras disciplinas.

Para los efectos de explicar este modo de ver el proceso de normalización, revisaremos las apreciaciones que hiciera el filósofo argentino Risieri Frondizi (1988) ${ }^{9}$, quien, sin mencionar directamente la instalación de la filosofía disciplinar a inicios del XX como normalización filosófica, nos da una perspectiva de este desarrollo como la instalación de una filosofía que logra independizarse como disciplina. Para él, este impulso estuvo dado por el pensamiento positivista que los denominados fundadores fueron abandonando a medida que sus búsquedas reflexivas fueron transitando hacia otras sensibilidades.

Respecto a la filosofía latinoamericana, este autor nos dirá que no hay por qué hacer vanos esfuerzos en buscar ciertos modos de pensamiento y temáticas que, al ya estar avanzadas, no debiésemos por qué sobrescribir en ellas. No hay por qué volver a descubrir la rueda si ya hace años está siendo parte de las labores de las distintas culturas (Frondizi, 1988). Aquí la filosofía no tiene un lugar de residencia, al menos permanente, ni mucho menos la filosofía tiene esa evidente forma europea que impide la reflexión propia. La filosofía es universal, filosofía sin más.

En los términos de (y gracias a) la normalidad filosófica, la filosofía en América Latina tendría la condición y posibilidad histórica de emprender vuelo autónomo. Es decir, la filosofía a la vez que se "institucionaliza"(y normaliza), se despega cada vez más de otras corrientes de pensamiento y posicionamientos que, al estar apegadas a la ella, la harían perder el carácter tan propio que la

\footnotetext{
${ }^{9}$ Las reflexiones utilizadas son originalmente de 1948.
} 
caracterizaría. Una de las depuraciones más evidentes que la filosofía habría comenzado a hacer en esta situación de normalización, sería la separación entre filosofía y política. Respecto a esta separación de la filosofía de otros quehaceres del pensar humano, Frondizi nos dirá lo siguiente: "De nuevo habrá que separar la actividad filosófica de otras actividades espirituales que la acompañan si queremos evitar otra clase de equívocos. Del principio general de la unidad del espíritu humano y de la cultura se ha querido derivar la imposibilidad de distinguir la filosofía de las preocupaciones estéticas, políticas, sociales, etc." (1988: 212-213).

Estas preocupaciones por la precisa delimitación de la filosofía, se deben a la peculiaridad de nuestra historia. Frondizi nos dice que la labor filosófica que realizaron los hombres en Hispanoamérica, siempre fue acompañada de otras preocupaciones, nunca hubo pensamiento filosófico "puro"; es decir, la filosofía nunca se desarrolló "como preocupación propia o aislada sino en íntima relación con actividades y preocupaciones literarias, políticas y docentes (Frondizi, 1988: 213). Esto ha provocado que la filosofía siempre haya estado en condición de sierva de otras disciplinas e inquietudes. No obstante, Frondizi es muy claro en señalar que su percepción de la filosofía no es una totalmente abstraída de todo acontecer sociopolítico. Cito al pensador argentino: "No se crea que estamos reduciendo la filosofía a su magro sentido académico o a la labor estrictamente sistemática. Lejos de nuestro ánimo el intento de reservar el término "filosofía" para una actividad estrecha y alejada de toda preocupación vital, o negarle tal carácter a la faena problemática y de búsqueda.” (1988: 214).

Luego de advertirnos que la filosofía no es ese tal altar del pensamiento inmaculado, en donde no hay cabida para las preocupaciones prosaicas, Frondizi nos brinda su concepción de qué es lo que entiende por reflexión filosófica:

Será filosófica aquella meditación que, por su tema, su alcance y su sentido se mueva dentro de lo que se entiende tradicionalmente por filosofía, para usar una expresión un tanto general pero que se ajusta a lo que queremos significar sin arrojarnos a la complicada y discutible determinación de la esencia de la filosofía. En otras palabras, habrá filosofía cuando se medite en función de lo filosófico y no se ponga tal actividad al servicio de intereses y preocupaciones políticas, literarias, etc. (Frondizi, 1988: 214).

La filosofía para Frondizi será muy similar al modelo que se inicia con la normalización que estipula Romero, es decir, un tipo de reflexión desde el cual se pueden dar ciertas soluciones y formas de pensar la realidad, pero que en sí -y esto ya no es de Romero sino Frondizi- no es una bandera de lucha ni está 
al servicio de algo; a la vez, Frondizi no quiere dar a entender que la filosofía sea una inmanencia epistemológica que solo tenga la capacidad de reflexionar desde y para sus propios intereses. Nos parece que desde sus propias palabras quedar mejor explicitado este punto:

No se crea que estamos haciendo la apología de una filosofía encerrada dentro de sí misma, de una filosofía académica que teme contaminarse en su contacto con la vida. Nada de eso; creemos que la filosofía es, fundamentalmente, filosofía de la vida, de la experiencia humana. Pero la vida y la experiencia humana constituyen el objeto de la meditación, y no fijan límites, imponen dirección o dan normas a la meditación. Una cosa es que la vida constituya la realidad que estudia la filosofía -su objeto de meditación- y otra muy distinta que se pretenda que la filosofía esté al servicio de intereses vitales inmediatos. (1988: 219).

Así, la filosofía latinoamericana será la filosofía tal como se conoce en la cultura occidental, pero desde los pensadores que habitan esta parte del mundo. Según nos parece, es válido aprender un cierto modo de reflexión, sin embargo, una visión así al parecer no repara del todo en las condiciones de cómo se ha impuesto este ejercicio del saber, cómo es que se adquiere, bajo qué términos es adquirido y, también, qué modos reflexivos invalida y aparta de su campo. Normalizar en otras palabras también es naturalizar, y el problema de naturalizar es que se dejan de ver cosas, mecanismo, normas y formas que terminan, al decir de Cerutti (2000), subrepticiamente operando.

\section{Palabras Finales: La normalización y el caso de Chile de inicios del XX}

Al darle importancia en este trabajo al proceso de la instalación de la filosofía en la cultura del continente, lo que podríamos identificar con la parte menos revisada de la definición que le diera Francisco Romero al concepto de normalización, queremos revisar, como hemos anunciado, algunas escuetas apreciaciones sobre la idea de Chile y América Latina que circulaban en la cultura de dicho país.

Para comenzar, definiremos lo que Bernardo Subercaseaux entiende por imaginario: "El concepto de imaginario implica un conjunto más o menos coherente o articulado de representaciones. El imaginario es histórico y datado, puesto que en cada época o, más bien, en cada escenificación de tiempo histórico, las sociedades constituyen representaciones para referirse o conferir algún sentido a lo real" (Subercaseaux: 275).

Una de las representaciones más repetitivas que tendremos sobre Chile en los filósofos de dicho país, en este período, será la idea de Chile como un país excepcional en la región. Idea que, como han indicado 
ciertos estudiosos, toma fuerza luego del triunfo chileno en la guerra de expansión territorial, tanto al sur como al norte, que realiza el país. La expansión hacia el norte, con la que Bolivia pierde su acceso al mar y Perú pierde otro tanto, fue la que dio mayor cuerpo a la idea de una raza chilena superior. ${ }^{10}$

En relación a esto, cuando Miguel Da Costa Leiva hace referencia al Chile de Enrique Molina, principalmente al que se expresa en el libro Lo que ha sido el vivir-para ese entonces inédito-, muestra el siguiente contexto de época que consideramos muy útil:

En ella se expresa cómo el chileno de ese entonces tenía la ilusión de creer que este país era el primer pueblo de América Hispana en cuanto a prosperidad, calidad de raza, progreso de sus instituciones políticas y sociales. Se pensaba que los demás países de la América morena no soportaban una comparación positiva con Chile, a cada uno de ellos se les encontraban defectos que sobrevaloraban la calidad del hombre chileno. En ese parangón no se salvaba ni Estado Unidos ni la gran mayoría de los países europeos. Existía la creencia general que, de Europa, sólo Francia, Inglaterra y Alemania tenían suficientes reservas espirituales para enseñarnos. Tal vez la demostración empírica de este mito explique el por qué Chile mirará acentuadamente hacia estos países, a fines del siglo XIX y buena parte del presente (Da Costa Leiva 1999: 157-158).

En cuanto a la supuesta excepcionalidad chilena, Da Costa Leiva, tal como otros autores, tendrá en vista la Guerra del Pacífico como suceso clave.

Para el chileno de cierto grado de cultura que participó en las campañas del Pacífico, no podían pasar inadvertidos ciertos valores arraigados de la idiosincrasia nacional que hicieron posible el triunfo en general y en cada contienda en que se tranzó el ejército chileno. En general el triunfo de una guerra siempre trae asociado la expresión de sentimientos de superioridad, sentimientos que se trasladan al plano espiritual y afectivo desde el campo de batalla. (1999: 158).

Algo similar expondrá Enrique Molina en 1920 a través de un diálogo que entablaría con una persona de nacionalidad peruana, que aparece en su libro Por las dos Américas. El diálogo hace relación a la Guerra del Pacífico y a las ventajas que Chile habría tenido respecto a sus países vecinos; en cuanto a lo dicho por el peruano, esto sería así:

El desenlace de la Guerra del Pacífico fue desgraciadamente una cosa natural y lógica. Nosotros teníamos que ser vencidos por un motivo racial. Como usted sabe, las tres cuartas partes de nuestra población están formadas de indios y con la indiada no se pueden hacer buenos soldados.

\footnotetext{
${ }^{10}$ Hay autores que plantean que el imaginario de la excepcionalidad de Chile parte prácticamente desde su nacimiento. Para esto ver Pinto, Jorge (2008). "Proyectos de la elite chilena del siglo XIX (I)". En Revista Alpha N²6, Departamento de Humanidades y Artes, Universidad de Los Lagos.
} 
¿Cómo íbamos a combatir con éxito con el pueblo de ustedes, compuestos de fuertes mestizos o de tipos de raza blanca? [sic] (Molina, 1920: 20).

En lo relatado por Collier y Sater en su Historia de Chile, y en referencia a la libre expresión en la prensa nacional, la cual reflejaría el cambio cultural que habían ofrecido los triunfos bélicos sobre nuestros países hermanos:

La Moneda no silenció las críticas de la prensa o del Congreso. Se seguía disfrutando y abusando de la libertad de expresión y de reunión. Éstos eran logros valiosos y demostraban, asimismo, cuánto había cambiado el país desde la primera guerra contra la Confederación peruano-boliviana. Y resultaba evidente que había cambiado sustancialmente también en otras áreas. El sentido de superioridad chileno, ya bien desarrollado, se vio aumentado por la victoria. Un nuevo conjunto de héroes ocupó su lugar en el panteón nacional. No obstante, lo más importante de todo fue que la guerra le había dado al país un nuevo territorio cuyas ricas reservas de salitre prometían una fuente constante y abundante de ingresos. El futuro parecía aún más brillante. (Collier; Sater, 1999: 137).

Esta imagen de nación, puede ser explicada desde las ideas que expone Bernardo Subercaseaux respecto al tiempo integrador de Chile, como él lo denomina. Según nos dice, este tiempo puede ser rastreado entre los años 1900 a 1930, y esto no sería solamente para Chile, sino que abarcaría al continente completo. Para Subercaseaux, este período estaría caracterizado por el rol homogenizador del Estado, donde se "percibía los particularismos y las diferencias culturales como un estorbo" (2011: 212). La idea era integrar, pero desde un marco bastante rígido, ya que "se buscó integrar a nuevos sectores sociales, pero siempre en una perspectiva asimilacionista o de mestizaje y no de diversidad" (Subercaseaux, 2011: 213). Sin embargo, el caso de Chile podría ser rastreado desde antes de lo indicado. Para Bernardo Subercaseaux: "Hay países como Chile en que ya desde el siglo XIX el discurso de la homogeneidad se implementó por la elite y por el Estado con extraordinario éxito, generando la autoconciencia de una nación que se percibió como culturalmente europea. De allí también el mito de la "Suiza o la Inglaterra de América Latina", de allí también el mito (nacionalista) de la excepcionalidad de Chile en el contexto latinoamericano." (2011: 213).

Una de estas características excepcionales de Chile, tendría que ver con el clima. El clima más frío haría, para un Enrique Molina de 1917, que los habitantes del país poseyeran cualidades que los haría diferentes al resto: "Hablando en conjunto, la luz i la libertad, van creciendo a medida que se avanza al Sur de Panamá. El Ecuador es menos medioeval que Colombia, el Perú lo es menos que el Ecuador, i Chile aun menos que el Perú. [sic] (1917: 26). 
Respecto a tal determinismo geográfico que incidiría en la capacidad intelectual y de actuar del hombre, Molina nos dice: "El sol de los trópicos afecta al organismo humano de tal manera que se desvanecen las reglas morales de los países fríos" (1917: 41). Podría hacerse notar el sesgo racista que contienen estas reflexiones, sin embargo, las teorías que se tenían sobre las relaciones existentes entre ambiente y seres humanos, estaban sumamente arraigadas en el imaginario de la época. En un estudio sobre la muestra de Chile en la Exposición Iberoamericana de Sevilla en 1929, realizado por Sylvia Dümer (2012), la autora nos explica los distintos postulados que resaltaban las diferencias existentes entre los habitantes de zonas calurosas, con los habitantes de las zonas templadas. Llegando a la conclusión de que en las zonas templadas era más efectivo el desarrollo del intelecto que en las calurosas, como las zonas tropicales tan abundantes en un continente como el latinoamericano.

Esto, por ejemplo, podemos verlo también en Jorge Millas [1943] del siguiente modo:

El caso de Chile es de una precocidad de este tipo. Entre los países de América, se distingue por ciertos rasgos propios de la plenitud histórica, que sólo a través de varios siglos pueden consolidarse. El fundamental de todos estos rasgos a que aludo, el que regimenta a los demás, imponiéndoles su sello, es, sin duda, el de la sobriedad espiritual. Chile es un pueblo sobrio. Esta sobriedad suya, como que está en contraste con otros caracteres pueriles de su imagen histórica, es una anticipación de la que ha de ser, sin duda, su personalidad definitiva en sus tiempos de sazón [...] Lo contrario de sobriedad es frenesí, o, como debería decirse en América, tropicalismo. En virtud de un sinnúmero de razones geográficas, históricas, raciales, culturales - que las hay en los órdenes más diversos-, los chilenos ponen en sus cosas siempre la fuerza adecuada para el efecto justo. (2009: 26-27).

Continuando con el nacionalismo filosófico de Millas:

El frenesí es una cualidad dionisíaca; la sobriedad, apolínea. Chile posee, pues, una indiscutible mentalidad apolínea, que explica el ponderado ritmo clásico de su evolución cívica y de su organización institucional, y el tipo mesurado, digno, de su literatura, que revela, por, sobre todo, una espiritualidad equilibrada, proporcionada, justa, no obstante, la profundidad que suele alcanzar en ocasiones. Por eso, sin duda, hay en nuestro país menos chabacanería que en otros países de América, no obstante haberla, y no escasamente. Por eso también, nuestra sensibilidad es más profunda; junto a otros pueblos podemos, a lo mejor, aparecer frívolos, cuando lo que en verdad ocurre es que somos menos superficiales (2009: 27). 
Entre estas ideas del período, podemos encontrar otras reflexiones sobre América que resultarían importantes, pero por temas de extensión se hace imposible abordarlos aquí ${ }^{11}$. Estas ideas serán desarrolladas por Luis Oyarzún ${ }^{12}$ (1944) y Clarence Finlayson ${ }^{13}$ (1969). Ellos están pensando una América Latina que suele considerarse más bien ausente en los pensadores chilenos de la época, sin embargo, el trabajo de archivo cada vez da más luces de lo contrario ${ }^{14}$.Una idea de normalización vinculada a la cultura, como la propuesta, consideramos que será una útil herramienta para comenzar a levantar una historia que logre tomar cada vez más distancia de los diagnósticos que diera, por ejemplo, un Carlos Ossandón allá por los años 80':

Desgraciadamente nuestros investigadores, en Chile, no se han preocupado suficientemente - como sí lo han hecho de forma más significativa los mexicanos y argentinos- de develar los rasgos más sobresalientes de nuestra historia intelectual, el sentido y significado que ha tenido la marcha del pensamiento entre nosotros, limitándose éstos, las más de las veces, a consignar datos, hechos intelectuales, obras, figuras aisladas, etc., sin tomarse mayormente el trabajo de percibir las estructuras explicativas, las intuiciones fundamentales, las ideas-fuerza, la teleología, en definitiva, que ilumina nuestras distintas épocas históricas. (Ossandón, en Devés, 1980: 31).

Por último, consideramos que iniciar la búsqueda de las distintas reafirmaciones de sujeto que operan en los filósofos chilenos, ayuda a no perdernos en el bosque de búsquedas inquisidoras que acusan las trabas que existirían en nuestro pensar, en vez de revisar cómo nos hemos pensado desde la filosofía y así encontrar ciertas líneas que de seguro nos darán ciertas respuestas y más de una sorpresa.

\footnotetext{
${ }^{11}$ La idea es desarrollarlas en un trabajo posterior que dé cuenta específicamente de las reflexiones sobre Chile y América Latina de los filósofos chilenos de la primera mitad del siglo XX. De todas formas, algo se ha esbozado en el cap.1 de la tesis en que se basa este trabajo.

12 Oyarzún, L. (1944). "Nota sobre la inquietud americana", en Atenea, LXXVII (XXI), 164-170.

${ }^{13}$ Hablamos de los trabajos "Expresión de la cultura americana" de 1945 y "Consideraciones sobre la cultura filosófica en la América Latina" de 1953, ambos aparecidos en su Antología (1969).

${ }^{14}$ En la revista Atenea de la Universidad de Concepción (que circula desde 1924 a la fecha), aparecen varios artículos y comentarios que dan cuenta del imaginario que hay de Chile y América en la época que aludimos. Ahí se han podido recoger interesantes reflexiones y puntos de vista sobre las percepciones de "los propios hijos de su tiempo".
} 


\section{Referencias bibliográficas}

Ardiles O. (1973), "Bases para una des-trucción de la historia de la filosofía en la América Indo-ibérica. Prolegómenos para una filosofía de la liberación". En VV.AA., Hacia una filosofía de la liberación latinoamericana (págs. 7-26). Buenos Aires: Editorial BONUM.

Beorlegui C. (2004), Historia del pensamiento filosófico latinoamericano. Una búsqueda incesante de la identidad. Bilbao: Universidad de Deusto.

Bertranou J. D. (2012), "Algo más que una relación epistolar: Francisco Romero, Edgar S. Brightman y el personalismo norteamericano". Cuyo, Anuario de Filosofía Argentina y Americana, 29 (2), 133-160.

Betancur J. C. (2015), "Para un análisis crítico del concepto de normalización filosófica". Universitas Philosophica, 65 (32), 137-157.

Casalla M. (1986), "Más allá de la "normalidad filosófica", nuevas tareas para la filosofía latinoamericana contemporánea". Revista de Filosofía Latinoamericana y Ciencias Sociales (11), 10-32.

Cerutti H. (1986), Hacia una metodología de la historia de las ideas (filosóficas) en América Latina. Guadalajara: Universidad de Guadalajara.

(1986), "Filosofía latinoamericana e historia de la filosofía". En Hacia una metodología de la 777historia de las ideas (filosóficas) en América Latina (págs. 75-111). México: Universidad de Guadalajara.

(2001), "La normalización filosófica y el problema de la filosofía iberoamericana en la primera mitad del siglo XX". En Experiencias en el tiempo (págs. 39-66). Morelia: Jitanjáfora.

(2009), "Normalización... y después". En Y seguimos filosofando (págs. 90-105). La Habana: Editorial de Ciencias Sociales. 

(2000), Filosofar desde nuestra América. Ensayo problematizador de su modus operandi. México: Grupo Editorial Miguel Ángel Porrúa - UNAM.

Da Costa Leiva M. (1999), "El pensamiento de Enrique Molina Garmendia". En E. Devés, J. Pinedo, \& R. Sagredo, El pensamiento chileno en el siglo XX (págs. 154-197). México: Fondo de Cultura Económica. Devés Valdés, E. (2000). Del Ariel de Rodó a la CEPAL (1900-1950). Santiago: Editorial Biblios - Centro de Investigaciones Diego Barros Arana.

Dümmer Scheel S. (2012), "Metáforas de un país frío. Chile en la Exposición Iberoamericana de Sevilla en 1929". Arteologie (3).

Dussel E. (1970), "Francisco Romero, filósofo de la modernidad en la Argentina". Cuyo. Anuario de historia del pensamiento argentino, VI, 79-106.

Figueroa Casas V. (2000), "Arturo Andrés Roig y la metodología de la historia de las ideas en América Latina". Islas, 42 (125), 123-149.

Finlayson C. (1969), Antología. Santiago: Andrés Bello.

Fornet-Betancourt R. (2000), "Para un balance crítico de la filosofía iberoamericana en la llamada etapa de los fundadores". Anuario de Filosofía Argentina y Americana (17), 117-132.

Frondizi R. (1988), ¿Hay una filosofía iberoamericana?". En J. Gracia, \& I. Jaksic, Filosofía e identidad cultural en América Latina (págs. 211-227). Caracas: Monte Avila Editores.

Giannini H. (1978), "Experiencia y Filosofía (a propósito de la filosofía en latinoamérica). Revista de Filosofía, 16 (1-2), 25-32.

Gracia J. \& Jaksic I. (1988), Filosofía e identidad cultural en América Latina. Caracas: Monte Avila Editores. 
Mignolo W. (2003), Historias locales/diseños globales. Colonialidad, conocimientos subalternos y pensamiento fronterizo. Madrid: Akal.

Millas J. (2009), Idea de la Individualidad. Santiago: Universidad Diego Portales.

Miró Quesada F. (1974), Despertar y proyecto del filosofar latinoamericano. México: Fondo de Cultura Económica.

Molina E. (1920), Por las dos Américas. Notas y reflexiones. Santiago: Casa Editorial Minerva.

Molina E. \& Rowe L. S. (1917), Las democracias americanas $i$ sus deberes. Santiago: Imprenta Universitaria.

Ossandón C. (2016), "Ensayismo y destino en Enrique Molina". Literatura y Linguística , 97-114. (1984), Hacia una filosofía latinoamericana. Santiago: Nuestra América Ediciones.

Oyarzún L. (1944), "Nota sobre la inquietud americana". Atenea, LXXVII (XXI), 164-170.

Ramaglia, D. (2010), "Condiciones y límites del proceso de institucionalización de la cultura filosófica argentina a comienzos del siglo XX". SOLAR, 6 (6), 13-39.

Roig A. A. (1988), "Función actual de la filosofía en América Latina". En J. J. Gracia, \& I. Jakcic, Filosofía e Identidad cultural en América Latina (págs. 363-384). Caracas: Monte Avila Editores. (2008), El pensamiento latinoamericano y su aventura. Buenos Aires: Ediciones el Andariego. (2002), Ética del poder y moralidad de la protesta. Respuestas a la crisis moral de nuestro tiempo. Mendoza: EDIUNC. (1993), Rostro y filosofía de América Latina. Mendoza: EDIUNC. 

(1981), Teoría y crítica del pensamiento latinoamericano. México: Fondo de Cultura Económica.

Romero F. (1951), Filosofía de la persona. Buenos Aires: Losada. (1947), Filósofos y problemas. Buenos Aires: Losada. (1952), Sobre la filosofía en América. Buenos Aires: Editorial Raigal.

Santos-Herceg J. (2013), "Filosofía y universidad en la época de los "patriarcas". Enrique Molina Garmendia y Pedro León Loyola". SOLAR, 9 (9), 109-131.

(2017), "Textos testimoniales en la biblioteca filosófica. Apuntes para pensar su inclusión". Revista de Filosofía, 73, 337-350.

(2010), Conflicto de Representaciones. América Latina como lugar para la filosofía. Santiago: Fondo de Cultura Económica.

Silva Martínez G. (2009), "La filosofía antipositivista". En E. Dussel, E. Mendieta, \& C. Bohórquez, El pensamiento filosófico latinoamericano, del Caribe y "latino" [1300-2000] (págs. 268-277). Mexico: CREFAL - Siglo XXI.

(2009), "Normalización de la filosofía chilena. Un camino de clausura disciplinar". Universum, 2 (24), 172-191.

Subercaseaux B. (2011), Historia de las ideas y de la cultura en Chile, Vol. II, tomo IV. Santiago: Editorial Universitaria.

Torchia Estrada J. C. (2009), "Francisco Romero". En E. Dussel, E. Mendieta, \& C. Bohórquez, El pensamiento filosófico latinoamericano, del Caribe y "latino" [1300-2000] (págs. 868-870). México: Siglo XXI - CREFAL. 
Vrsalovic Muñoz S. (2018), "Entre dos interpretaciones de la normalización de la filosofía: ¿apertura o cierre de la filosofía latinoamericana?". En VV.AA., Filosofía e Historia de la Ciencia en el Cono Sur (págs. 451-464). Córdoba: AFHIC.

Zea L. (1983), "Romero y la normalidad filosófica latinoamericana". En VV.AA, Francisco Romero. Maestro de la filosofía latinoamericana (págs. 169-181). Caracas: Sociedad Interamericana de Filosofía. (1976), El pensamiento latinoamericano. Barcelona: Ariel. 